\title{
A KINETIC STUDY OF THE ELECTROREDUCTION OF ANODICALLY FORMED COBALT OXIDE LAYERS
}

\author{
C. A. Gervasi,* S. R. Biaggio, †. R. Vilche and A. J. Arvia \\ Instituto de Investigaciones Fisicoquimicas Teóricas y Aplicadas (INIFTA), Facultad de Ciencias Exactas, \\ Universidad Nacional de La Plata, Sucursal 4, Casilla de Correo 16, (1900) La Plata, Argentina
}

(Received 29 January 1991)

\begin{abstract}
The kinetics of the electroreduction of anodically formed cobalt oxide layers in different carbonate-bicarbonate aqueous solutions were investigated using combined voltammetric and potential step techniques. The composition of the electrolyte was varied to cover wide $\mathrm{pH}$ and ionic strength ranges. The electroreduction reaction can be explained through a nucleation and three-dimensional growth process, involving cobalt phase formation from either soluble $\mathrm{Co}$ (II) or $\mathrm{Co}$ (III) species.
\end{abstract}

Key words: cobalt oxides, electroreduction, kinetics, voltammetry, chronoamperometry.

\section{INTRODUCTION}

The electrochemical behaviour of anodic oxide films on cobalt in neutral and slightly alkaline solutions either anodically produced or prepared by chemical procedures has been studied rather extensively in the last decade covering several aspects particularly related to corrosion and passivation of cobalt, and the electrocatalytic properties of spinel-type cobalt oxides. Cobalt oxide layers of electrochemical interest offer a rather complex chemistry involving a relatively large number of structures and stoichiometries which depend to a large extent on the preparation procedure. The literature published up to 1982 in relation to this matter, particularly referred to the corrosion and passivation of cobalt in aqueous solutions has been reviewed in Refs[1] and [2], and that concerning spinel-type cobalt oxide electrodes is given in Refs [3-5].

The voltammograms of cobalt electrodes in neutral and alkaline solutions present three pairs of conjugated peaks related to reactions involving changes in the oxidation state of cobalt and the appearance of new phases[6]. The relative contributions of these reactions depend on a large number of variables, some of them inherent to the proper electrochemical systems and others to the potential routine applied to the electrode.

The present work describes the kinetics of the electroreduction of cobalt oxide layers prepared through potential controlled anodization of cobalt in carbonate-bicarbonate buffers, and the participation of nucleation and growth processes in the electroreduction reactions. The selection of the carbonate-bicarbonate buffer was made because data on the

*Present address: Centro de Investigación y Desarrollo en Tecnologia de Pinturas (CIDEPINT), 52 entre 121 y 122, (1900) La Plata, Argentina. Member of the Carrera del Investigador CIC.

†Permanent address: Departamento de Química, Centro de Ciencias e Tecnología, Universidade Federal de Sâo Carlos, Sâo Carlos, Brazil. anodic behaviour of cobalt electrodes in these solutions is already available. In addition, these systems which are of practical interest in $\mathrm{CO}_{2}$ absorbing media, offer the possibility of controlling the $\mathrm{pH}$ at the reaction layer.

\section{EXPERIMENTAL}

The experimental set-up was the same as already described in previous publications[6]. "Specpure" cobalt (Johnson Matthey Chemicals Ltd.) in the form of either fixed wires $(0.5 \mathrm{~mm}$ diameter, $0.25 \mathrm{~cm}^{2}$ apparent area) or discs $\left(0.070 \mathrm{~cm}^{2}\right.$ apparent area) was used for working electrodes in $x \mathrm{M} \quad \mathrm{KHCO}_{3}+y \mathrm{M} \quad \mathrm{K}_{2} \mathrm{CO}_{3}$ solutions at $25^{\circ} \mathrm{C}$ $(0.075 \leqslant x \leqslant 2.5 ; 0.0005 \leqslant y \leqslant 1.5)$ covering the 8.3$10.5 \mathrm{pH}$ range. The electrolyte solutions were prepared from analytical grade (p.a. Merck) reagents and triply distilled water previously boiled to remove $\mathrm{CO}_{2}$. At each $\mathrm{pH}$, the values of $x$ and $y$ were set to cover a wide ionic strength range by keeping the $\mathrm{HCO}_{3}^{-} / \mathrm{CO}_{3}^{2-}$ concentration ratio constant. Cobalt electrodes were successively polished with 400 and 600 grade emery papers and 1.0 and $0.3 \mu \mathrm{m}$ grit alumina-acetone suspensions, and afterwards repeatedly rinsed with triply distilled water. Finally, cobalt electrodes were cathodically polarized for $1 \mathrm{~min}$ at potentials sufficiently negative to produce a net hydrogen evolution. The counter electrode was a large area $\mathrm{Pt}$ plate. Potentials were measured against a sce reference electrode properly shielded and connected through a Luggin-Haber capillary tip, but in the text they are referred to the nhe scale.

Experiments were made under purified $\mathrm{N}_{2}$ gas saturation by employing the following perturbing potentials: (i) single (STPS) and repetitive (RTPS) triangular potential sweeps both as symmetric and asymmetric profiles between preset cathodic $\left(E_{\mathrm{scc}}\right)$ and anodic $\left(E_{s,}\right)$ switching potentials at a scan rate, $v$; (ii) combined potential scans including potential holdings during time $\tau$; (iii) combined potential scans and potentiostatic steps. The schema of the 


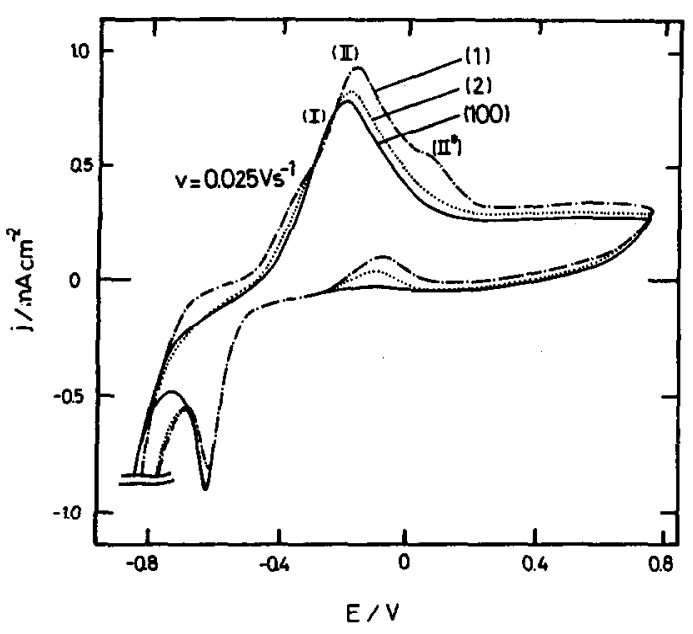

Fig. 1. Voltammograms run at $v=0.025 \mathrm{~V} \mathrm{~s}^{-1}$ between $E_{\mathrm{zcc}}=-0.86 \mathrm{~V}$ and $E_{\mathrm{s}, \mathrm{a}}=0.74 \mathrm{~V} ; 0.75 \mathrm{M} \mathrm{KHCO}_{3}+0.05 \mathrm{M}$ $\mathrm{K}_{2} \mathrm{CO}_{3}$ (pH 8.9). The 1st, 2nd and 100th cycles are indicated.

perturbing potential routine are shown in the corresponding figures as insets.

\section{RESULTS AND DISCUSSION}

The voltammogram of cobalt in quiescent

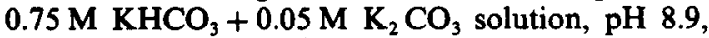
run at $v=0.025 \mathrm{~V} \mathrm{~s}^{-1}$ between $E_{\mathrm{s}, \mathrm{c}}=-0.86 \mathrm{~V}$ and $E_{\mathrm{a}, \mathrm{a}}=0.74 \mathrm{~V}$ (Fig. 1), in the active-to-passive transition potential range shows a main anodic peak at $c a$ $-0.17 \mathrm{~V}$ (peak II) and two satellite humps, one at $c a$ $-0.33 \mathrm{~V}$ (peak I) and another one at $0.07 \mathrm{~V}$ (peak II*). The reverse scans exhibit during the first cycles a slight reactivation of the electro-oxidation process at $c a-0.10 \mathrm{~V}$ which progressively decreases on cycling, and a well-defined cathodic peak at $c a-0.63 \mathrm{~V}$ preceding the HER potential region. Thermodynamic data[7-10] indicate that peaks I and II lie within the stability potential range of $\mathrm{Co}$ (II) species, whereas peak II* appears in the region where, in principle, the formation of $\mathrm{Co}$ (III) becomes possible.

The electroreduction voltammograms of cobalt oxide layers produced by fixing $E_{\mathrm{s}, \mathrm{a}}$ either at the potential of peak I or at the potential of peak II, run at different $v$ for a constant amount of anodically formed cobalt oxide, show two different behaviours according to both the value of $E_{\mathrm{s}, \mathrm{a}}$ and the amount of cobalt oxide produced at $E_{\mathrm{s}, \mathrm{a}}$. The electroreduction of relatively thin cobalt oxide layers formed at $E_{\mathrm{s}, \mathrm{a}}=-0.39 \mathrm{~V}$ seems to obey the kinetics of a reversible electrochemical reaction under diffusion control, whereas the electroreduction of relatively thick cobalt oxide layers produced at $E_{\mathrm{s}, \mathrm{a}}=-0.16 \mathrm{~V}$ appears to follow an ohmic resistance control kinetics[6]. The latter kinetic behaviour is also obtained for a cobalt oxide layer which has been produced in $0.075 \mathrm{M} \mathrm{KHCO}+0.0005 \mathrm{M} \mathrm{K}_{2} \mathrm{CO}_{3}(\mathrm{pH} \mathrm{8.3)}$, by applying a linear potential scan from $E_{\mathrm{s}, \mathrm{c}}=-0.86 \mathrm{~V}$ to $E_{\mathrm{s}, \mathrm{a}}$ at $v=0.01 \mathrm{~V} \mathrm{~s}^{-1}$, and subsequently holding the potential for $\tau=30 \mathrm{~s}$ at a value of $E_{\mathrm{s}, \mathrm{a}}$ more positive than the potential of peak II $^{*}$. In this case, for $q_{p, c}$ the cathodic voltammetric charge density, of about $3 \mathrm{mC} \mathrm{cm}^{-2}$, both $j_{\mathrm{p}, \mathrm{c}}$ and $E_{\mathrm{p}, \mathrm{c}}$ change linearly with $v_{\mathrm{c}}^{1 / 2}$ (Fig. 2).

The potentiostatic electroreduction of cobalt oxide layers was also investigated through the analysis of the corresponding current transients by setting $E_{\mathrm{f}}$, the electroreduction potential in the range between $E_{\mathrm{s}, \mathrm{a}}$ and the voltammetric electroreduction peak potential. For those cobalt anodic oxide layers produced at values of $E_{\mathrm{s}, \mathrm{a}}$ lower than the potential of peak II, a continuous electroreduction current decay is observed at any $E_{\mathrm{f}}$ value following a $j$ vs $t^{-1 / 2}$ law (Fig. 3a). However, when $E_{8, a}$ is set at potentials more positive than that of peak II, and $E_{\mathrm{f}}$ is fixed more negative than $-0.61 \mathrm{~V}$, the corresponding electroreduction current firstly decays to a small minimum value, $j_{\mathrm{m}}$ at time $t_{\mathrm{m}}$, later increases to reach a peaked value, $j_{\mathrm{M}}$ at time $t_{\mathrm{M}}$, and finally, decays to attain the stationary $\mathrm{HER}$ current value at $E_{\mathrm{f}}$ (Fig. $3 \mathrm{~b}-\mathrm{d}$ ). The values of $j_{\mathrm{M}}$ and $t_{\mathrm{M}}$ change according to $E_{\mathrm{f}}$ (Fig. 4).

The preceding results show that the potentiostatic electroreduction of those cobalt oxide layers involves two partially interacting processes which can be investigated separately by selecting the appropriate working conditions. Thus, the initial falling part of the electroreduction current transients exhibits a linear $j$ vs $t^{-1 / 2}$ relationship whose slope increases as $E_{\mathrm{f}}$ is set more negatively. This behaviour suggests that
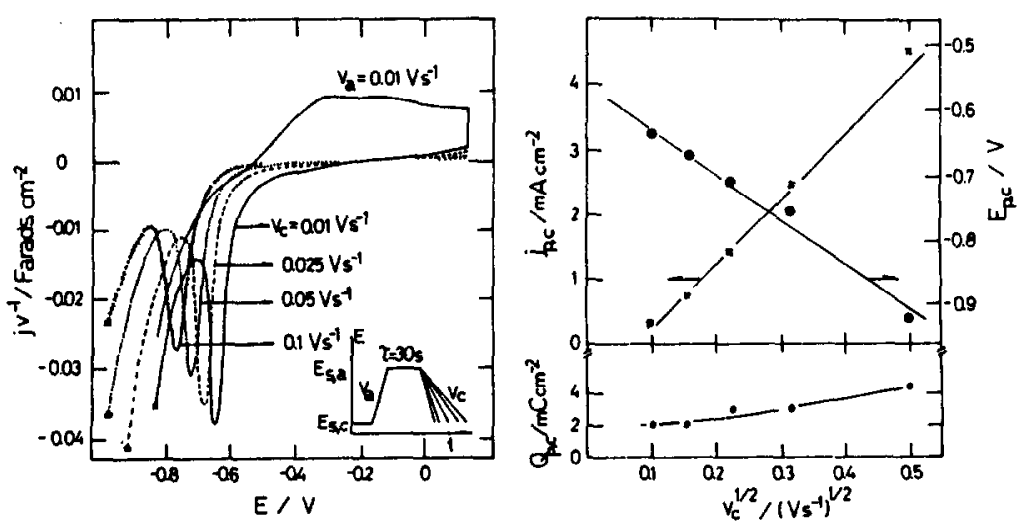

Fig. 2. Influence of $v$ on the voltammograms run in $0.075 \mathrm{M} \mathrm{KHCO}_{3}+0.0005 \mathrm{M} \mathrm{K}_{2} \mathrm{CO}_{3}$ (pH 8.3). The potential routine is indicated in the figure; $E_{\mathrm{s}, \mathrm{a}}=0.14 \mathrm{~V}$. The dependence of $j_{\mathrm{p}, \mathrm{c}}, E_{\mathrm{p}, \mathrm{c}}$ and $q_{\mathrm{p}, \mathrm{c}}$ are also shown. 


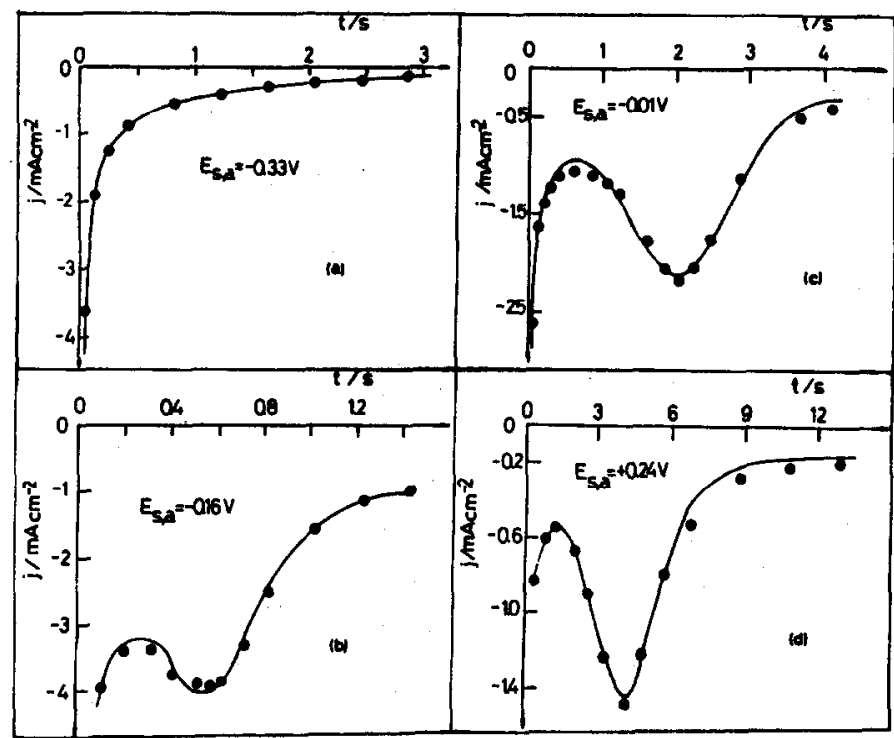

Fig. 3. Current transients recorded for $E_{\mathrm{s}, \mathrm{a}}=-0.33 \mathrm{~V}$ (a), $E_{\mathrm{s, \textrm {a }}}=-0.16 \mathrm{~V}$ (b), $E_{\mathrm{san}}=-0.01 \mathrm{~V}$ (c), and $E_{s, \mathrm{a}}=0.24 \mathrm{~V}$ (d) at $E_{\mathrm{f}}=-0.66 \mathrm{~V} ; 0.75 \mathrm{M} \mathrm{KHCO}_{3}+0.05 \mathrm{M} \mathrm{K}_{2} \mathrm{CO}_{3}$ (pH 8.9). Experimental (dots), and calculated data (full traces).

initially the electroreduction process obeys a simple diffusion law. In other words, the shorter time required for the process related to $j_{M}$ the more negative the value of $E_{\mathrm{f}}$ (Fig. 4). The rising part of the current transient after correction for the residual current of the initial diffusion controlled process, obeys a linear $j$ vs $t^{3}$ plot (Fig. 5). Such a phenomenological relationship is predicted by a three-dimensional (3-D) progressive nucleation and growth model, under charge transfer control, involving right circular cones nuclei distributed at random and a nuclei death correction[11]. Furthermore, a closer inspection of the electroreduction current transient (Fig. 5) still shows the appearance of an induction time, which is related to the formation of 3-D nuclei. A first indication of the agreement between experimental data

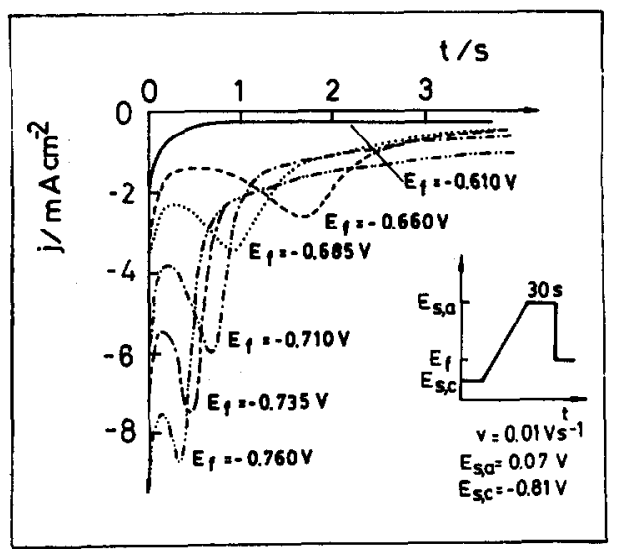

Fig. 4. Current transients recorded at different $E_{\mathrm{f}}$ values. The cobalt oxide layers were previously formed according to the potential program indicated at the inset; $0.75 \mathrm{M}$ $\mathrm{KHCO}_{3}+0.05 \mathrm{M} \mathrm{K}_{2} \mathrm{CO}_{3}(\mathrm{pH} 8.9) ; E_{8, \mathrm{a}}=0.07 \mathrm{~V}$. and the formalism of the preceding nucleation and growth model is given through the reduced variable test plot, i.e. $j / j_{M}$ vs $t / t_{M}$ (Fig. 6), by also taking into account for $j$ and $t$, the residual current and the induction time corrections, respectively.

According to the precedent model, the potentiostatic electroreduction current transient is described by the following equations:

$$
j(t)=\frac{P_{3}}{t^{1 / 2}}+P_{1}\left[1-\exp \left(-P_{2} t_{i}^{3}\right)\right] \exp \left(-P_{2} t_{i}^{3}\right)
$$

where

$$
\begin{gathered}
t_{i}=t-t_{\text {lag }}=t-P_{4} \\
P_{1}=z F k_{1} \\
P_{2}=\frac{\pi M^{2} k_{2}^{2} A}{3 \rho^{2}}
\end{gathered}
$$

and

$$
P_{3}=\frac{z F D^{1 / 2} \Delta c}{\pi^{1 / 2}}
$$

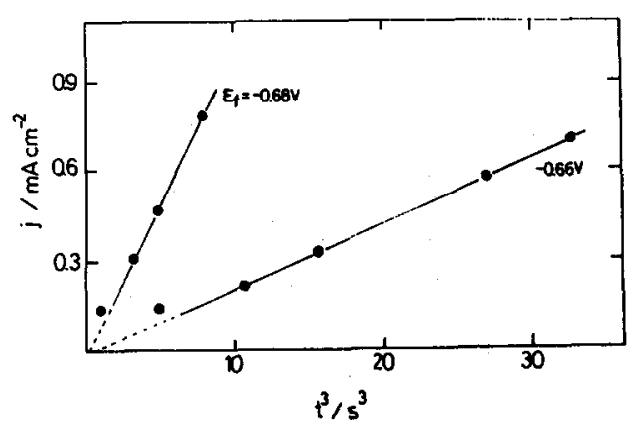

Fig. 5. $j$ vs $t^{3}$ plot for the rising part of the current transient $\left(t_{\mathrm{m}} \leqslant t \leqslant t_{\mathrm{M}}\right)$. Values of $j$ are corrected for the initial diffusional contribution to current decay; $0.075 \mathrm{M}$ $\mathrm{KHCO}_{3}+0.0005 \mathrm{M} \mathrm{K}_{2} \mathrm{CO}_{3}\left(\mathrm{pH} \mathrm{8.3)} ; E_{4 \mathrm{~s}}=0.14 \mathrm{~V}\right.$. 


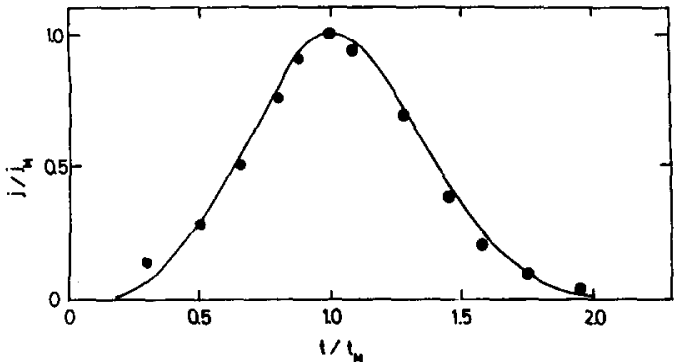

Fig. 6. Reduced variable test for current transients shown in Fig. 5; $E_{\mathrm{f}}=-0.66 \mathrm{~V}$; induction time $0.86 \mathrm{~s}$.

$k_{1}\left(\mathrm{~mol} \mathrm{~cm} \mathrm{~cm}^{-2} \mathrm{~s}^{-1}\right)$ and $k_{2}\left(\mathrm{~mol} \mathrm{~cm} \mathrm{~cm}^{-2} \mathrm{~s}^{-1}\right)$ stand for the new phase growth rate constants parallel and perpendicular, respectively, to the electrode surface; $M\left(\mathrm{~g} \mathrm{~mol}^{-1}\right)$ and $\rho\left(\mathrm{g} \mathrm{cm}^{-3}\right)$ are the molecular weight and the specific weight of the growing phase, respectively; $A$ (nuclei $\mathrm{cm}^{-2} \mathrm{~s}^{-1}$ ) is the nucleation rate constant; $D\left(\mathrm{~cm}^{2} \mathrm{~s}^{-1}\right)$ and $\Delta c\left(\mathrm{~mol} \mathrm{~cm}^{-3}\right)$ are the diffusion coefficient and the concentration gradient, respectively, of the diffusing species across the Nernst diffusion layer.

Data obtained at $\mathrm{pH} 8.3$ and 10.5 can be fitted with equation (1) as shown in Figs 7 and 8 . The consistency of the equation was assessed by leaving the parameters free under the control of the fitting procedure, particularly the value of $P_{4}$. In this way, physically significant values of those parameters were obtained for each working condition, under a systematic variation of both $E_{\mathrm{f}}$ and the electrolyte composition, as given in Figs 9 and 10 and summarized in Tables 1 and 2. The dependence of $k_{1}$ and $E_{\mathrm{f}}$ fits a Tafel equation with a slope, which becomes apparently independent of $\mathrm{HCO}_{3}^{-}$ion concentration and $\mathrm{pH}$ of the solution. Accordingly, the nucleation and growth process parallel to the substrate surface is practically independent of the solution composition (Fig. 11). Unfortunately, the same analysis is not directly applicable to $k_{2}$ as the value of the latter as well as the value of $A$ are derived from $P_{2}$, being both dependent on $E_{\mathrm{f}}$. Nevertheless, from the different

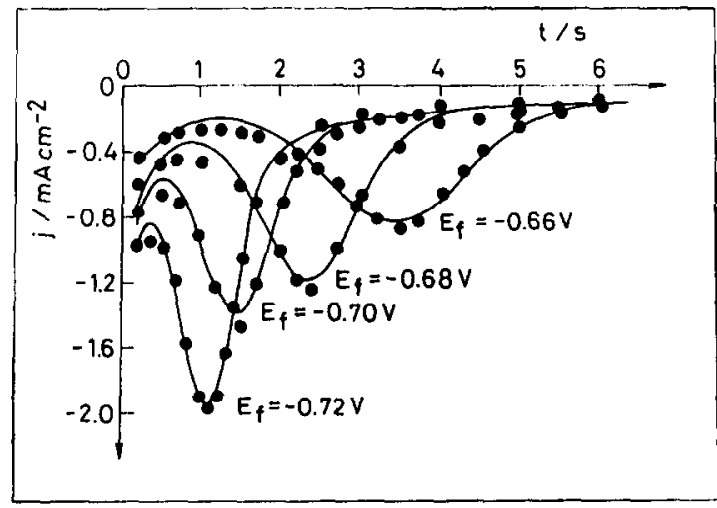

Fig. 7. Fitting of current transient data according to equation (1) (full traces); $0.075 \mathrm{M} \mathrm{KHCO}_{3}+0.0005 \mathrm{M}$ $\mathrm{K}_{2} \mathrm{CO}_{3}(\mathrm{pH} 8.3) ; E_{\mathrm{s}, \mathrm{a}}=0.14 \mathrm{~V}$ at different $E_{\mathrm{f}}$ values.

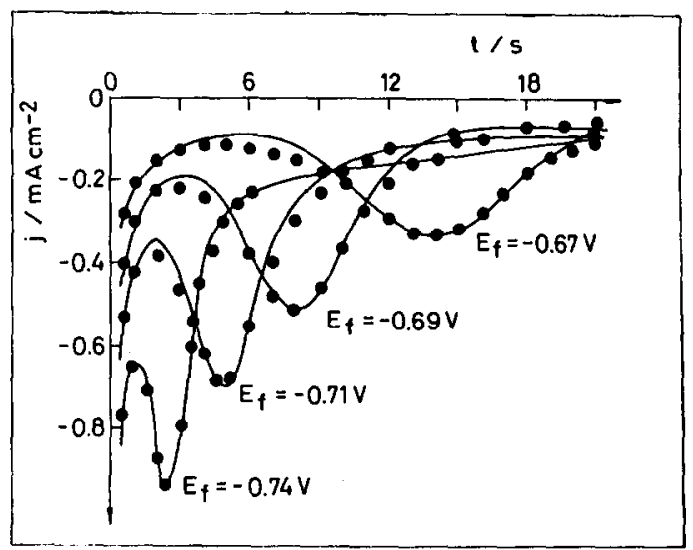

Fig. 8. Fitting of current transient data according to equation (1) (full traces); $0.075 \mathrm{M} \mathrm{KHCO}_{3}+0.15 \mathrm{M} \mathrm{K}_{2} \mathrm{CO}_{3}$ $(\mathrm{pH} 10.5) ; E_{\mathrm{s}, \mathrm{a}}=0.14 \mathrm{~V}$ at different $E_{\mathrm{f}}$ values.

experimental coefficients assembled in Table 1 (Fig. 9), one can observe that the growth process in depth becomes considerably more dependent on $\mathrm{HCO}_{3}^{-}$ion concentration, $\mathrm{pH}$, and $E_{\mathrm{f}}$ than the growth process in the direction parallel to the substrate surface.

From the potential dependence of $P_{3}$ (Fig. 10a) the variation of the surface concentration of the reacting species during the initial diffusional stage can be

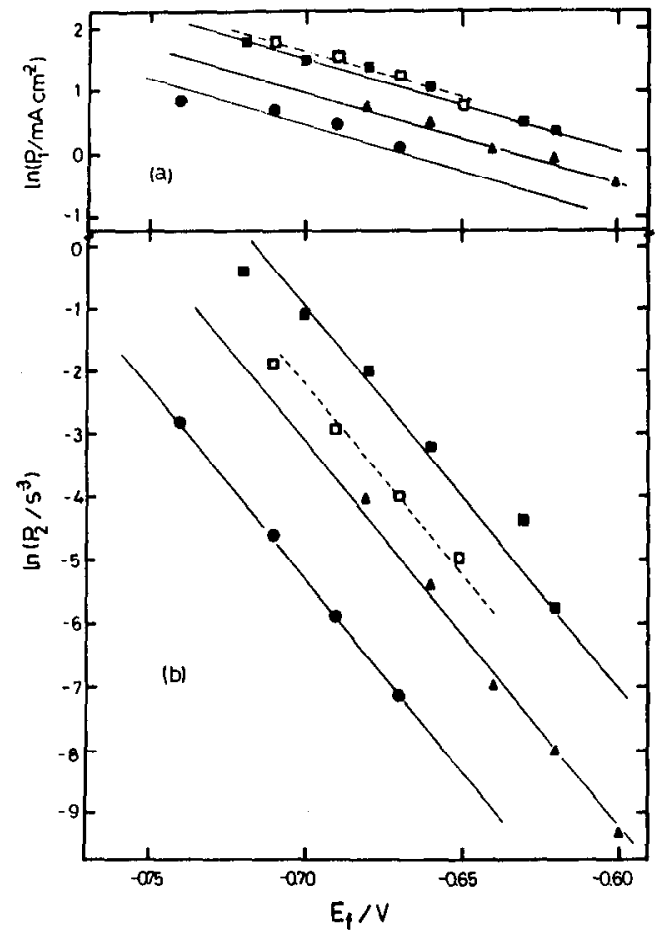

Fig. 9. Dependences of $P_{1}$ (a) and $P_{2}$ (b) on $E_{\mathrm{f}}$. Values of $P_{1}$ and $P_{2}$ were derived from the fitting procedure by using equation (1); $E_{s, 8}=0.14 \mathrm{~V}$. Electrolyte compositions: $0.75 \mathrm{M}$ $\mathrm{KHCO}_{3}+0.005 \mathrm{M} \mathrm{K}_{2} \mathrm{CO}_{3}$, pH $8.3(\square) ; 0.075 \mathrm{MKHCO}_{3}+$ $0.0005 \mathrm{M} \mathrm{K}_{2} \mathrm{CO}_{3}, \mathrm{pH} 8.3$ (回); $0.075 \mathrm{M} \mathrm{KHCO}_{3}+0.015 \mathrm{M}$ $\mathrm{K}_{2} \mathrm{CO}_{3}, \mathrm{pH} 9.5(\Lambda) ; 0.075 \mathrm{M} \mathrm{KHCO}+0.15 \mathrm{M} \mathrm{K}_{2} \mathrm{CO}_{3}$, $\mathrm{pH} 10.5(0)$ 


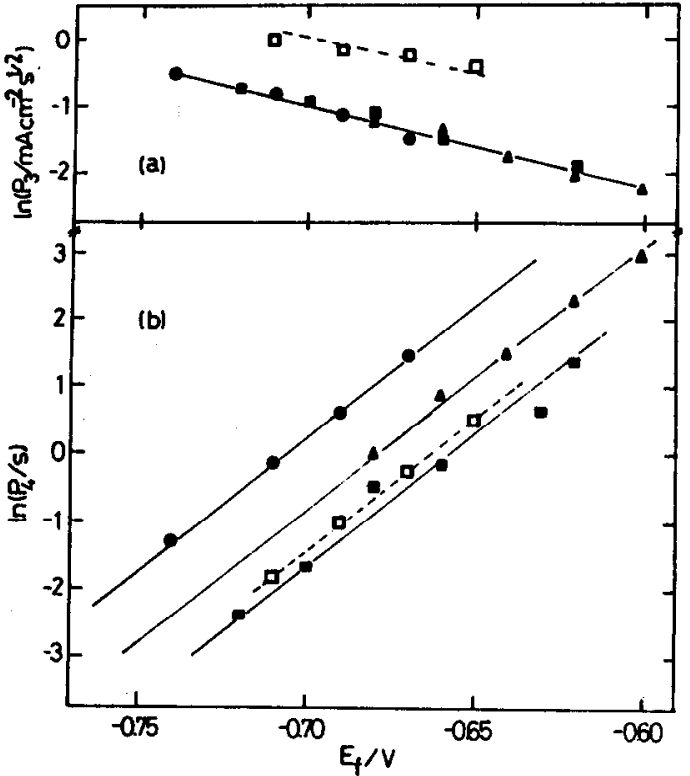

Fig. 10. Dependences of $P_{3}$ (a) and $P_{4}$ (b) on $E_{\mathrm{f}}$. Values of $P_{3}$ and $P_{4}$ derived from the fitting procedure by using equation (1); $E_{\mathrm{s}, \mathrm{a}}=0.14 \mathrm{~V}$. Electrolyte compositions: $0.75 \mathrm{M}$ $\mathrm{KHCO}_{3}+0.005 \mathrm{M} \quad \mathrm{K}_{2} \mathrm{CO}_{3}, \quad \mathrm{pH} \quad 8.3$ (口); $0.075 \mathrm{M}$ $\mathrm{KHCO}_{3}+0.0005 \mathrm{M} \mathrm{K} \mathrm{KO}_{3}, \mathrm{pH} 8.3$ (G); $0.075 \mathrm{M}$ $\mathrm{KHCO}_{3}+0.015 \mathrm{M} \quad \mathrm{K}_{2} \mathrm{CO}_{3}, \quad \mathrm{pH} \quad 9.5$ (A); $0.075 \mathrm{M}$ $\mathrm{KHCO}_{3}+0.15 \mathrm{M} \mathrm{K}_{2} \mathrm{CO}_{3}, \mathrm{pH} 10.5(\Theta)$

estimated by applying a simple Nernst diffusion layer concentration profile. The value of $P_{3}$ also fits a Tafel dependence on $E_{\mathrm{f}}$ with a slope close to the $-(2 R T / F)$ ratio. The values of $P_{3}$ become independent of $\mathrm{pH}$, but an increase of the ionic strength results in higher $P_{3}$ values. The latter at a constant $E_{\mathrm{f}}$ increase with the $\mathrm{HCO}_{3}^{-}$ion concentration, the apparent reaction order being 0.5 . The dependence of $P_{3}$ on $E_{\mathrm{f}}$ and $\mathrm{HCO}_{3}^{-}$concentration is rather complex as it reflects those dependences of $\Delta c$ entering the definition of

Table 1. Parameters used for fitting the electroreduction current decay data according to equation (1)

\begin{tabular}{cccc}
\hline$E_{\mathrm{f}} / \mathrm{V}$ & $P_{1} / \mathrm{mA} \mathrm{cm}^{-2}$ & $P_{2} / \mathrm{s}^{-3}$ & $q_{1} / \mathrm{mC} \mathrm{cm}^{2}$ \\
\hline-0.63 & 1.67 & 0.017 & $3.8 \pm 0.2$ \\
-0.66 & 2.83 & 0.051 & $4.4 \pm 0.3$ \\
-0.68 & 3.96 & 0.14 & $4.1 \pm 0.3$ \\
-0.70 & 4.37 & 0.34 & $3.4 \pm 0.2$ \\
-0.72 & 6.02 & 0.68 & $3.7 \pm 0.2$ \\
\hline
\end{tabular}

The value of $q_{1}$ was obtained from equation (7); $0.075 \mathrm{M} \quad \mathrm{KHCO}_{3}+0.0005 \mathrm{M} \quad \mathrm{K}_{2} \mathrm{CO}_{3} \quad(\mathrm{pH}$ 8.3).

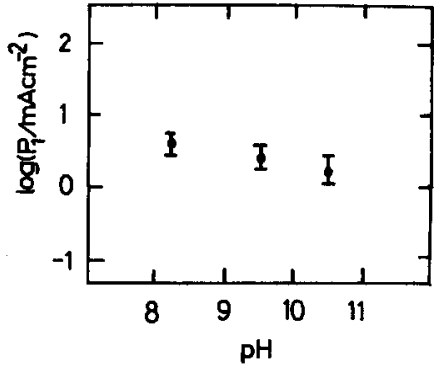

Fig. 11. Dependence of $P_{1}$ on solution $\mathrm{pH}$. Data taken from Fig. 9a; $E_{\mathrm{f}}=-0.7 \mathrm{~V} ; 0.075 \mathrm{M} \mathrm{KHCO}_{3}$

$P_{3}$. Nevertheless, the transport rate of the reacting species can be, in principle, related to $E_{\mathrm{f}}$ through the surface concentration of the species involved in the phase change process.

The values of $\boldsymbol{P}_{4}$ derived from the fitting procedure coincide with the induction times obtained from the $j$ vs $t^{3}$ plots (Fig. 5). On the other hand, the induction times fit a logarithmic dependence on $E_{\mathrm{f}}$ (Fig. 10b), the latter indicating presumably some degree of interaction between the two processes involved in the potentiostatic electroreduction of the cobalt oxide layer. It should be noted that when $E_{\mathrm{sa}}$ is set within the potential range comprising peaks II and $\mathrm{II}^{*}$, the value of $\boldsymbol{P}_{4}$ becomes zero (Fig. $3 \mathrm{~b}$, c), $i e$ the formation of 3-D nuclei requires no induction time. Otherwise, the dependence of $P_{4}$ on $E_{\mathrm{f}}$ fits also a Tafel line with the slope close to $R T / F$, the value of $P_{4}$ approaching a first-order $\mathrm{pH}$ dependence, but appears to be independent of $\mathrm{HCO}_{3}^{-}$ion concentration.

The electroreduction charge density comprised in the nucleation and growth processes can be calculated through the integral:

$$
q_{1}=\int_{0}^{\infty} P_{1}\left[1-\exp \left(-P_{2} t_{i}^{3}\right)\right] \exp \left(-P_{2} t_{i}^{3}\right) \mathrm{d} t_{i}
$$

which yields[11]

$$
q_{1}=0.54 P_{1}\left(1 / P_{2}\right)^{1 / 3} \text {. }
$$

The values of $q_{1}$ (Table 1 ) in those current transients depicted in Fig. 7 are directly comparable to those values obtained voltammetrically (Fig. 2), as both are related to the same potential routine and electrolyte composition.

The electroreduction charge density related to the first diffusional controlled process can be evaluated from the integral:

$$
q_{2}=\int_{0}^{P_{4}} \frac{P_{3}}{t^{1 / 2}} \mathrm{~d} t=2 P_{3} P_{4}^{1 / 2}
$$

Table 2. Parameters used for fitting the electroreduction current decay data according to equation (1)

\begin{tabular}{cclccc}
\hline$E_{\mathrm{f}} / \mathrm{V}$ & $P_{3} / \mathrm{mA} \mathrm{cm}^{-2} \mathrm{~s}^{1 / 2}$ & $P_{4} / \mathrm{s}$ & $q_{2} / \mathrm{mC} \mathrm{cm}^{-2}$ & $C \mu \mathrm{F} \mathrm{cm}^{-2}$ & $q_{\mathrm{T}} / \mathrm{mC} \mathrm{cm}^{-2}$ \\
\hline-0.63 & 0.15 & 1.9 & $0.68 \pm 0.07$ & $883 \pm 70$ & $4.5 \pm 0.3$ \\
-0.66 & 0.23 & 0.86 & $0.43 \pm 0.04$ & $538 \pm 60$ & $4.9 \pm 0.4$ \\
-0.68 & 0.32 & 0.62 & $0.51 \pm 0.05$ & $622 \pm 60$ & $4.6 \pm 0.3$ \\
-0.70 & 0.38 & 0.19 & $0.33 \pm 0.04$ & $400 \pm 40$ & $4.7 \pm 0.4$ \\
-0.72 & 0.45 & 0.092 & $0.28 \pm 0.03$ & $322 \pm 35$ & $4.0 \pm 0.3$ \\
\hline
\end{tabular}

The value of $q_{2}$ was obtained from equation (8); $C$ denotes the integral capacity calculated over the $E_{\mathrm{s}, \mathrm{a}}$ to $E_{f}$ potential step; $q_{\mathrm{T}}$ stands for total charge density; $E_{\mathrm{sa}}=0.14 \mathrm{~V}$. 
The values of $q_{2}$, and accordingly the capacity values derived from $q_{2}$ (Table 2) are about 10 times greater than those expected from the double-layer charging from $E_{\mathrm{s}, \mathrm{a}}$ to $E_{\mathrm{f}}$. One can also observe (Table 2) that $q_{\mathrm{T}}$, the total charge density value, $q_{\mathrm{T}}=q_{1}+q_{2}$ agrees with those values resulting from voltammetry, particularly at high $v$.

The precedent analysis indicates that the electroreduction of anodically formed cobalt oxide layers is a complex reaction. In principle, one should expect that the corresponding reaction mechanism is consistent with the complex electro-oxidation pathway earlier advanced[6,12,13]. The anodization of cobalt up to peak $\mathrm{II}^{*}$ in carbonate-bicarbonate solutions yields a soluble $\mathrm{Co}(\mathrm{II})$ complex ion, ie $\mathrm{Co}\left(\mathrm{CO}_{3}\right)_{2}^{2-}$, and the formation of a composite $\mathrm{Co}$ (II) oxide-Co(II) carbonate layer[6]. At potentials more positive than the potential of peak $\mathrm{II}^{*}$, the chemical dissolution rate of surface products decreases due to the formation of a $\mathrm{Co}_{3} \mathrm{O}_{4}$-type passive layer. Once the latter has been formed, only minor amounts of soluble $\mathrm{Co}$ (II) species in solution can be detected through the rotating ring-disc technique during both the positive and the negative potential scans. Therefore, the initial shortrange electroreduction current decay fitting the $j$ vs $t^{-1 / 2}$ plot can be associated with the diffusioncontrolled reversible electroreduction of $\mathrm{Co}(\mathrm{II})$ complex yielding a cobalt overlayer on the substrate. This conclusion is consistent with the value of $D \cong 10^{-6} \mathrm{~cm}^{2} \mathrm{~s}^{-1}$ derived from $P_{3}$ (Fig. 10a) and the concentration of $\mathrm{Co}$ (II)-soluble species in the solution obtained from solubility data of $\mathrm{Co}$ (II) complexes in different electrolyte compositions[12]. The increase in the value of $P_{3}$ as the $\mathrm{HCO}_{3}^{-}$ion concentration is increased is consistent with the fact that the concentration of $\mathrm{Co}$ (II) complex in solution is directly proportional to the $\mathrm{KHCO}_{3}$ concentration.

The long-range electroreduction process which can be fitted through both equations (1) and (6) is detectable only when $E_{\mathrm{s}, \mathrm{a}}$ has been set sufficiently positive to accumulate a relatively thick $\mathrm{Co}$ (II) surface layer. The main process associated with the potentiostatic electroreduction of those thick layers should comprise a phase change such as either the conversion of $\mathrm{Co}$ (III) into $\mathrm{Co}$ (II) oxide layer, or the direct nucleation and growth of the cobalt overlayer from the discharge of $\mathrm{Co}$ (II) species, the reaction being preceded by a fast $\mathrm{Co}$ (III) to $\mathrm{Co}$ (II) conversion at the oxide layer. Accordingly, the induction time can be related to the time required to reach the threshold concentration of soluble $\mathrm{Co}$ (II) species at the reaction interface. Correspondingly, provided that $E_{\mathrm{s}, \mathrm{a}}$ exceeds the potential of peak II*, the greater $E_{\mathrm{s}, \mathrm{a}}$, the longer the time required for reaching the critical concentration of soluble Co(II) species. This is consistent with an oxide layer composition involving a $\mathrm{Co}$ (III)/Co(II) concentration ratio which increases with $E_{\mathrm{s}, \mathrm{a}}$. This description can explain the linear $\ln P_{4}$ vs $E_{\mathrm{f}}$ relationship (Fig. 10b) with a slope equal to $(26 \mathrm{mV})^{-1}$.
Finally, the residual long-term portion of the electroreduction current transients which becomes $E_{\mathrm{f}}$ independent is mainly associated with the hydrogen evolution reaction on the freshly formed cobalt overlayer.

\section{CONCLUSIONS}

A computer-aided analysis of results for the electroreduction of anodically formed cobalt oxide films allows discrimination between the mechanistic contributions related to the entire phase change process, evaluation of kinetic parameters related to the different processes, establishment of phenomenological relationships, and correlation of conclusions from the physical model with those ones previously obtained from electrochemical kinetics. The electroreduction process fits reasonably a two-stage electrochemical mechanism involving soluble $\mathrm{Co}$ (II) species. The latter, in addition to the passivating cobalt oxide layer, plays an important role in determining the cobalt overlayer produced through the electroreduction process.

Acknowledgement-This research project was financially supported by the Consejo Nacional de Investigaciones Cientificas y Técnicas and the Comisión de Investigaciones Científicas de la Provincia de Buenos Aires (CIC).

\section{REFERENCES}

1. H. Gomez Meier, J. R. Vilche and A. J. Arvia, J. electroanal. Chem. 134, 251 (1982).

2. H. Gomez Meier, J. R. Vilche and A. J. Arvia, J. electroanal. Chem. 138, 367 (1982).

3. B. N. Efremov, M. R. Tarasevich, G. I. Zakharkin and S. R. Zhukov, Elektrokhimiya 14, 1504 (1978).

4. R. Boggio, A. Carugati and S. Trasatti, J. appl. Electrochem. 17, 828 (1987).

5. M. R. Gennero de Chialvo, T. Kessler, A. Visintin W. E. Triaca and A. J. Arvia, J. appl. Electrochem., in press.

6. C. A. Gervasi, S. R. Biaggio, J. R. Vilche and A. J. Arvia, Corros. Sci. 29, 427 (1989).

7. W. K. Behl and J. E. Toni, J. electroanal. Chem. 31, 63 (1971).

8. N. Sato and T. Ohtsuka, J. electrochem. Soc. 125, 1735 (1978).

9. M. Pourbaix, Atlas of Electrochemical Equilibria in Aqueous Solutions, p. 322 . Pergamon Press-CEBELCOR, Oxford, Brussels (1966).

10. W. M. Latimer, The Oxidation States of the Elements and Their Potentials in Aqueous Solutions. Prentice-Hall, New York (1953).

11. R. D. Armstrong, M. Fleischmann and H. R. Thirsk, J. electroanal. Chem. 11, 208 (1966).

12. D. H. Davies and G. T. Burstein, Corros. Sci. 20, 973 (1980).

13. D. H. Davies and G. T. Burstein, Corros. Sci. 20,989 (1980). 